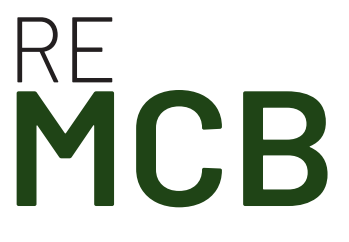

Revista Ecuatoriana de Medicina y Ciencias Biológicas Volumen 42. No. 1, Mayo 2021

\section{Formación de biofilm en aislados clínicos de Staphylococcus aureus y Staphylococcus epidermidis de Quito y el Puyo}

\author{
Biofilm formation in clinical isolates of Staphylococcus aureus and \\ Staphylococcus epidermidis from Quito and Puyo
}

Andrés Sanguano ${ }^{1}$, María Fernanda Yauri' e lliana Alcocer ${ }^{1 *}$
'Laboratorio de Microbiología, Escuela de Ciencias Biológicas, Pontificia Universidad Católica del Ecuador, Quito, Ecuador.

*Autor de correspondencia: iralcocer@puce.edu.ec

Recibido 15-01-2020

Aceptado 23-03-2021

DOI: 10.26807/remcb.v42i1.885

e-ISSN 2477-9148

๑) 2021. Este es un artículo publicado en acceso abierto bajo una licencia CC BY 4.0

Como citar este artículo: Sanguano A., Yauri MF, Alcocer I. 2021. Biofilm formation in clinical isolates of Staphylococcus aureus and Staphylococcus epidermidis from Quito and Puyo. Revista Ecuatoriana de Medicina y Ciencias Biológicas 42(1): 37-53. doi: 10.26807/remcb.v42i1.885
Resumen.- Staphylococcus aureus y S. epidermidis presentan capacidad de formar biofilm. El biofilm es una matriz polimérica que facilita la supervivencia bacteriana y es codificado por el operon ica que involucra cuatro genes: icaA, icaB, icaC e icaD. El objetivo del presente estudio fue identificar la formación de biofilm en aislados clínicos de Staphylococcus aureus y Staphylococcus epidermidis por prueba cualitativa en Agar Rojo Congo (ACR) e identificación de presencia de genes del locus ica mediante reacción en cadena de polimerasa (PCR). Se analizaron 99 aislados clínicos de S. aureus y S. epidermidis provenientes de tres hospitales de tercer nivel en Quito y el Puyo. Se usó como control la cepa American Type Culture Collection de S. aureus ATCC ${ }^{\circledR} 25923$. Con la prueba de ACR se identificaron 29 aislados productores de biofilm: casi negro 3,00\%, negro con $16,00 \%$ y muy negro $10,00 \%$. En contraste con la prueba de PCR se identificó 70,00 $\%, 35,00 \%, 26,00 \%$ y 66,00 \% positivos para icaA, icaB, icaC e icaD, respectivamente. La prueba de ACR es menos eficiente para identificar aislados productores de biofilm, mientras que la amplificación de genes ica es más efectiva para determinar la capacidad que tiene S. aureus o $S$. epidermidis para producir biofilm.

Palabras clave: agar rojo Congo, biofilm, estafilococos, factores de virulencia, genes ica.

Abstract.- Staphylococcus aureus and S. epidermidis are capable to produce biofilm. The biofilm is a polymeric matrix that ease the bacterial survival and is produced by the locus ica which has four genes icaA, icaB, icaC and icaD. The objective of this study was to detect the presence of isolates that can produce biofilm in clinical isolates of Staphylococcus aureus and Staphylococcus epidermidis by Congo red agar (CRA) and gen detection of the locus ica genes by polymerase chain reaction (PCR). 99 clinical isolates of S. aureus and S. epidermidis from three third level hospitals in Quito and Puyo were analyzed. The strain of S. aureus ATCC ${ }^{\oplus} 25923$ from the American Type Culture Collection was used as a control. With the CRA test 29 isolates with a phenotype capable of producing biofilm were identified: almost black 3,00 \%, black 16,00 \% and very black $10,00 \%$. Nevertheless, with the PCR test $70,00 \%, 35,00 \%, 26,00 \%$ y $66,00 \%$ of the isolates were positive for icaA, icaB, icaC e icaD, respectively. The CRA test is less effective identifying isolates capable of producing biofilm, whereas the gene amplification of the ica genes is more effective at establishing whether an isolate of S. aureus or S. epidermidis is capable of producing or not.

Keywords: biofilm, Congo red agar, ica genes, staphylococci, virulence factors 


\section{Introducción}

Staphylococcus es un género de bacterias Gram positivas anaerobias facultativas, inmóviles, no esporuladas, productoras de la enzima catalasa y fermentadoras de glucosa. Estas bacterias son consideradas comensales al encontrarse en la piel y en las membranas mucosas del humano (Kleinschmidt et al. 2015). Su nombre proviene de los vocablos griegos staphyle (racimo de uvas) y kokkus (baya) que describen la forma en la que estas bacterias se ven bajo el microscopio (Pahissa 2009). Las colonias aisladas en medio sólido son redondas, de borde liso, convexas y con una superficie brillante (Cavallini 2005).

Las bacterias de este género se pueden separar en dos grupos basándose en la capacidad de algunas especies para producir la enzima coagulasa: las bacterias coagulasa positivas, como S. aureus, y coagulasa negativas, como S. epidermidis (Granslo 2012). Dentro de ambos grupos, las especies de mayor importancia médica son S. aureus, S. epidermidis y S. saprophyticus, aunque otras especies son potencialmente capaces de producir un cuadro patológico (Cavallini 2005).

La identificación de las bacterias que forman parte del género inicia con tinción Gram, para la descripción morfológica, pruebas de catalasa y oxidasa, y determinación de metabolismo anaerobio/fermentativo mediante el empleo de agar manitol salado (Koneman y Allen 2008).

Staphylococcus aureus (Rosenbach 1884) es considerado uno de los principales patógenos bacterianos responsables de infecciones comunitarias y relacionadas con el cuidado de la salud (Jaśkiewicz et al. 2019). Es una bacteria muy resistente al calor, la desecación y puede crecer en condiciones de alta salinidad. Esto facilita que el 20,00 \% de la población sea portadora permanente de esta bacteria en fosas nasales y el 60,00 \% actúan como portadores intermitentes (Carr et al. 2018).

Uno de los factores que complican el tratamiento de infecciones estafilocócicas son los factores de virulencia que las bacterias presentan. Estos elementos confieren a las bacterias la capacidad de ser más patogénica u obtener una ventaja de supervivencia. Entre los principales factores que le brindan a S. aureus su patogenicidad se destacan: la toxina de shock tóxico, producción de enzima coagulasa, producción de toxinas citolíticas, toxinas exfoliativas y la leucocidina de Panton-Valentine (Ji 2007). Gracias a éstas, S. aureus puede causar distintas enfermedades, dependiendo del sitio de infección, y desencadenar: endocarditis, fibrosis, neumonía necrotizante, shock tóxico y sepsis (Lim et al. 2014). La Organización Mundial de la Salud (OMS) desde el año 2017 ha incluido a Staphylococcus aureus en la lista de las bacterias para las que se necesitan urgentemente nuevos antibióticos, ubicándose en la prioridad 2: elevada (OMS 2017).

S. epidermidis (Winslow y Winslow 1908) Evans 1916, es una bacteria que forma parte de la microbiota de la piel y la mucosa de los seres humanos. Es capaz de sobrevivir a altas concentraciones de salinidad y se diferencia principalmente de S. aureus por su incapacidad de producir la enzima coagulasa (Otto 2009). Esta bacteria actúa como probiótico, evitando la colonización de las superficies corporales por bacterias patogénicas. En la piel, S. epidermidis fermenta el glicerol en ácido butírico y ácido acético, los cuales inhiben la colonización de S. aureus (Traisaeng et al. 2019).

En los últimos años, S. epidermidis se ha convertido en un patógeno frecuente, demostrando su habilidad para colonizar los nichos que un ambiente hospitalario ofrece (Heilmann et al. 2019). Entre los factores que facilitan a S. epidermidis causar una infección son: un sistema inmune comprometido o inmaduro (Dong et al. 2018), individuos que hayan pasado por intervenciones quirúrgicas (Kleinschmidt et al. 2015) y presencia de dispositivos médicos permanentes que ofrecen superficies de colonización (Oliveira et al. 2018).

El crecimiento de casos de S. epidermidis asociado a infecciones intrahospitalarias se debe a la producción de un biopolímero extracelular conocido como biofilm. Éste protege a las bacterias contra el sistema inmune del huésped y sirve como barrera contra tratamientos antibióticos (Heilmann et al. 2019). 
El biofilm es una estructura común entre varios microorganismos, siendo una estructura fuerte y dinámica que brinda capacidad de adhesión y cohesión, propiedades mecánicas, fuentes de nutrientes, resistencia a drogas, resistencia al estrés ambiental y al sistema inmune del huésped. A éstas características se suman que provee de resistencia contra antibióticos, desinfectantes y antisépticos. El biofilm provee tolerancia contra deshidratación y luz ultravioleta. En el ambiente hospitalario, los aislados productores de biofilm, incrementan los costos generados en el cuidado de la salud y aumentan la permanencia del paciente, complicando aún más los cuadros infecciosos (Santos et al. 2018).

Existen dos tipos de biofilm conocidos en estafilococos, la adhesina intercelular de polisacáridos (PIA, por sus siglas en inglés) y el biofilm PIA independiente (Arciola et al. 2015). El biofilm de tipo PIA o también conocido como poli-N-acetilglucosamina (PNAG) consiste de cadenas de poli- $\beta$ (1-6)-N-acetilglucosamina, un glicosoaminoglicano linear que proporciona la adhesión intercelular de las células bacterianas (Arciola et al. 2015). Tanto en S. aureus como en S. epidermidis, el biofilm es codificado por el Operon ica, conformado por cuatro genes (icaA, icaD, icaB e icaC). Estos genes codifican transferasas y deacetilasas que producirán cadenas con monómeros de $\mathrm{N}$-acetilglucosaminas, que al final crearán las delgadas capas que constituyen el biofilm (Heilmann et al. 2019).

El biofilm de tipo PIA independiente es generado por diversas proteínas como la proteína asociada a biofilm (Bap), la proteína asociada a la acumulación (Aap), generalmente asociadas a estafilococos coagulasa negativos. Otro tipo de proteínas de superficie como SasG, SasC, proteina A, proteínas de unión a la fibronectina, también contribuyen a la formación de este tipo de biofilm (Arciola et al. 2015).

La producción de biofilm se gatilla por la presencia de factores externos como etanol, isopropanol y $\mathrm{NaCl}$, que al estar presentes en ciertas concentraciones pueden requerir de mayor o menor producción de biofilm (O'Gara 2007; Luther et al. 2015). Otro factor regulador de la expresión de biofilm es el elemento transponible IS256, que se inserta en diferentes sitios del operon ica, inhibiendo la síntesis de biofilm en una cepa productora de biofilm. (Hennig y Ziebuhr 2008). Este es un proceso reversible, ya que después de unas cuantas generaciones las cepas pueden volver a producir biofilm (Ziebuhr et al. 1999; Hennig y Ziebuhr 2008).

El objetivo del presente estudio fue identificar la formación de biofilm tipo PIA en aislados clínicos de Staphylococcus aureus y Staphylococcus epidermidis por prueba cualitativa en Agar Rojo Congo (ACR) e identificación de genes del locus ica por PCR. Teniendo así un diagnóstico temprano que ayudaría a la prevención de complicaciones en el tratamiento de infecciones estafilocócicas. Los tratamientos deben adaptarse dependiendo de la complejidad del biofilm que produzcan las bacterias, por la necesidad de usar diferentes tipos de agentes dispersores, que en conjunto con los antibióticos puedan actuar sobre las bacterias. Un riesgo de la dispersión del biofilm es que las colonias que se desprenden colonicen otros órganos, por lo que se recomienda realizar terapias combinadas de agentes dispersores con drogas antimicrobianas sistémicas (Zapotoczna et al. 2016).

\section{Materiales y Métodos}

Población de estudio.- Se empleó aislados clínicos donados por dos hospitales de tercer nivel de la ciudad de Quito y un hospital de tercer nivel de la ciudad del Puyo, durante el periodo de octubre del 2016 a mayo del 2017. Los aislados provienen de procesos infecciosos como: secreción ocular, vaginal, traqueal, faríngeo, abscesos, sangre, líquido espinal, líquido cefalorraquídeo, heridas y además se incluyeron catéteres que fueron sembrados en medios sólidos específicos. Los aislados fueron identificados como S. epidermidis o S. aureus en los hospitales mediante el uso de pruebas bioquímicas. Éstos fueron transportados en placas de agar nutriente y medios de transporte Stuart al Laboratorio de Microbiología de la Escuela de Ciencias Biológicas de la Pontificia Universidad Católica del Ecuador (PUCE). La identificación de los aislados fue confirmada por desorción láser asistida por la matriz con detección de masas por tiempo de vuelo (Matrix-assited laser desorption/ionization time-of-flight mass spectrometry) por sus siglas en inglés MALDI-TOF en URANTICORP S.A., Guayaquil. El estudio también empleó 
la cepa de Staphylococcus aureus ATCC ${ }^{\circledR} 25923$ como referencia. Los aislados obtenidos forman parte de la Colección Bacteriana - Quito Católica (CB-QCA) y se les confirió un código propio de la colección. Para su procesamiento, las bacterias fueron reaisladas en placas de agar manitol salado (BBL ${ }^{\mathrm{TM}} \mathrm{BD}$ ) para verificación de su identificación y evidencia de ausencia de contaminación.

A partir de los aislados obtenidos sobre las placas de agar manitol salado, éstos fueron transferidos y sembrados en tubos que contenían 5,0 mL de caldo Infusión Cerebro Corazón (BHI por sus siglas en inglés, $\mathrm{BBL} \mathrm{L}^{\mathrm{TM}} \mathrm{BD}$ ) a $37^{\circ} \mathrm{C}$ por 18 horas. Luego de la incubación, a cada tubo se le añadió $30 \%$ de glicerol, y se realizaron 4 alícuotas en microtubos de 1,5 mL. Dos alícuotas fueron almacenadas a $-20^{\circ} \mathrm{C}$ y 2 alícuotas fueron almacenadas a $-80^{\circ} \mathrm{C}$.

Extracción de ADN.- La extracción se realizó a partir de los aislados conservados a - $20{ }^{\circ} \mathrm{C}$. Para su reactivación, las bacterias fueron cultivadas en caldo BHI (Difco $\left.{ }^{T M}\right)$ durante 18 - 24 horas a 35 ${ }^{\circ} \mathrm{C}$. Después, los aislados se sembraron sobre placas de agar manitol salado (BBL ${ }^{\mathrm{TM}} \mathrm{BD}$ ) durante 18 - 24 horas a $35^{\circ} \mathrm{C}$. Finalmente, al tercer día se realizó una transferencia de los aislados obtenidos de la placa a caldo Tripticasa de Soya (TSB, por sus siglas en inglés) (Difco ${ }^{\text {TMM }}$ ) durante 18 horas a 35 ${ }^{\circ} \mathrm{C}$. Con los cultivos en TSB se utilizó el kit de extracción comercial de ADN"Wizard ${ }^{\varpi}$ Genomic DNA Purification kit" (PROMEGA ${ }^{\oplus}$ ) siguiendo las indicaciones del fabricante para extracción de ADN de bacterias Gram positivas. La calidad y cantidad de ADN fue determinado con NanoDrop ${ }^{\text {TM }}$ 2000 (Thermo Scientific ${ }^{T M}$ ).

Pruebas cualitativas.- Las pruebas cualitativas de expresión de biofilm se realizaron mediante el uso de agar Rojo Congo. Para su preparación se siguió el protocolo propuesto por Petrelli et al. (2006) que empleó: BHI agar (BBL ${ }^{\mathrm{TM}} \mathrm{BD}$ ); 0,8 g/L de Rojo Congo (BDH Chemicals Ltd.) y enriquecido con $36 \mathrm{~g} / \mathrm{L}$ de glucosa para fomentar la producción de biofilm de tipo PIA. Los aislados obtenidos sobre placas de agar Manitol Salado $\left(B B L^{\mathrm{TM}} \mathrm{BD}\right)$ fueron transferidos a placas de agar Rojo Congo, con incubación por 18 horas a $37^{\circ} \mathrm{C}$, seguido de 12 horas a temperatura ambiente para continuar con las lecturas. El rojo Congo cambia el color de las colonias ante la presencia de los polisacáridos producidos para la producción del biofilm. Si las bacterias producen biofilm, las colonias serán de color negro. Los aislados que carezcan de esta capacidad fueron visualizados mostrando un color rojo (Freeman et al. 1989).

Los resultados se evaluaron según la coloración de las colonias en el medio, basándose en las escalas colorimétrica obtenidas de Arciola et al. (2002) que consta de seis categorías: 1) muy rojo, 2) rojo, 3) rojo obscuro, 4) casi negro, 5) negro y 6) muy negro.

Identificación de genes mediante PCR.- Mediante el uso de la reacción en cadena de la polimerasa (PCR) fueron detectados los genes ica (icaA, icaB, icaC e ica D). El volumen total de las reacciones de amplificación fue de $15 \mu \mathrm{L}$ que contenían: 7,5 $\mu \mathrm{L}$ de GoTaq ${ }^{\oplus}$ Green Master Mix (PROMEGA ${ }^{\oplus}$ ); 0,6 $\mu \mathrm{L}$ de ADN; 0,6 $\mu \mathrm{L}$ de cebador forward; 0,6 $\mu \mathrm{L}$ de cebador reverse y $5,5 \mu \mathrm{L}$ de agua grado molecular UltraPure ${ }^{\mathrm{TM}}$ Distilled water (Invitrogen).

Para Staphylococcus epidermidis se utilizaron cebadores para los genes icaA, icaB, icaC e icaD (Macrogen). Estos cebadores fueron tomados de la publicación de Paluch-Oleś et al. (2011) (Tabla 1) y se utilizaron las mismas condiciones propuestas por el autor, excepto por las temperaturas de templado de icaA, icaB e icaC que emplearon $52,3^{\circ} \mathrm{C}, 57,6^{\circ} \mathrm{C}$ y $40,6^{\circ} \mathrm{C}$ respectivamente. Para Staphylococcus aureus se utilizaron los cebadores icaA e icaD (Macrogen) descritos por Haddad et al. (2018) (Tabla 2) utilizando las mismas condiciones de amplificación descritas en el estudio.

Los amplicones obtenidos por PCR fueron analizados en gel de agarosa al $1 \%$ mediante electroforesis, que incluyó un marcador de peso molecular de 100 pb (Tracklt ${ }^{\text {TM }} 100$ pb ADN Ladder, Invitrogen). El proceso de tinción del gel se realizó con fluorocromo SYBR ${ }^{\text {TM }}$ Gold 10.000x (Invitrogen) sumergiendo el gel en esta solución durante 1 hora en un lugar oscuro. Los resultados fueron fotografiados utilizando el fotodocumentador Molecular Imager ${ }^{\circledR}$ Gel Doc $^{\text {TM }}$ XR+ System (Bio-Rad). 
Tabla 1. Cebadores utilizados en la detección de genes codificantes para la producción de biofilm en Staphylococcus epidermidis

\begin{tabular}{|c|c|c|c|}
\hline Cebadores $^{*}$ & Secuencias del cebador & $\begin{array}{l}\text { Longitud del } \\
\text { producto }\end{array}$ & $\begin{array}{c}\text { Condiciones de } \\
\text { PCR }\end{array}$ \\
\hline icaA forward & 5'-GACCTCGAAGTCAATAGAGGT-3' & $814 \mathrm{pb}$ & $30 \mathrm{~s} 95^{\circ} \mathrm{C}$ \\
\hline \multirow[t]{3}{*}{ ica $A$ reverse } & 5'-CCCAGTATAACGTTGGATACC-3' & & $30 \mathrm{~s} 52,3^{\circ} \mathrm{C}$ \\
\hline & & & $1,5 \min 72^{\circ} \mathrm{C}$ \\
\hline & & & 30 ciclos \\
\hline icaB forward & 5'-ATGGCTTAAAGCACACGACGC-3' & $526 \mathrm{pb}$ & $1 \min 95^{\circ} \mathrm{C}$ \\
\hline \multirow[t]{3}{*}{$i c a B$ reverse } & 5'-TATCGGCATCTGGTGTGACAG-3' & & $1 \min 57,6^{\circ} \mathrm{C}$ \\
\hline & & & $1,5 \min 72^{\circ} \mathrm{C}$ \\
\hline & & & 30 ciclos \\
\hline icaC forward & 5'-ATAAACTTGAATTAGTGTATT-3' & $989 \mathrm{pb}$ & $30 \mathrm{~s} 95^{\circ} \mathrm{C}$ \\
\hline \multirow[t]{3}{*}{ icaC reverse } & 5'-ATATATAAАACTCTCTTAACA-3' & & $1 \min 40.6^{\circ} \mathrm{C}$ \\
\hline & & & $1,5 \min 72^{\circ} \mathrm{C}$ \\
\hline & & & 30 ciclos \\
\hline icaD forward & 5'-AGGCAATATCCAACGGTAA-3' & $371 \mathrm{pb}$ & $1 \min 94^{\circ} \mathrm{C}$ \\
\hline \multirow[t]{3}{*}{$i c a D$ reverse } & 5'-GTCACGACCTTTCTTATATT-3' & & $1 \min 59^{\circ} \mathrm{C}$ \\
\hline & & & $2,5 \min 72^{\circ} \mathrm{C}$ \\
\hline & & & 30 ciclos \\
\hline
\end{tabular}

\section{Resultados}

Población de estudio.- Durante el periodo de colecta se obtuvieron 40 aislados del primer hospital de Quito, de los cuales 24/40 fueron identificados como S. epidermidis y 16/40 aislados como S. aureus. En el segundo hospital de Quito se colectaron 50 aislados, de los cuales 37/50 aislados correspondieron a S. epidermidis y 13/50 se identificaron como S. aureus. Finalmente, en el hospital de la ciudad del Puyo se colectaron 9 aislados de S. aureus. El total de aislados obtenidos fue de 99 aislados clínicos (61/99 S. epidermidis y 38/99 S. aureus). En el análisis se incluyó como cepa control a Staphylococcus aureus ATCC ${ }^{\circledast}$ 25923. Todos los aislados fueron identificados usando el método MALDI-TOF.

Pruebas cualitativas.- Mediante las pruebas cualitativas en agar Rojo Congo se establecen fenotipos relacionados con la producción de biofilm y se clasifican en las variantes: casi negro, negro y muy negro. Las variaciones muy rojo, rojo y rojo obscuro se relacionan con la ausencia de biofilm (Figura 1).

En el primer hospital de Quito 14/40 (35,00 \%) aislados tuvieron fenotipos positivos para la producción de biofilm, de los cuales 9 aislados fueron S. epidermidis y 5 aislados fueron S. aureus. En el segundo hospital de Quito 13/50 (26,00 \%) aislados fueron positivos, donde 12 aislados correspondían a S. epidermidis y un aislado a S. aureus. En el hospital del Puyo solamente 1/9 $(11,11 \%)$ aislado mostró un fenotipo positivo a la producción de biofilm. En total de los aislados clínicos positivos a la presencia de biofilm determinado bioquímicamente mediante agar rojo Congo fue de 28/100 (28,28 \%). Presentó también un fenotipo positivo la cepa ATCC ${ }^{\bullet}$ S. aureus 25923. Totalizando 29 aislados positivos para la producción de biofilm.

Los fenotipos más dominantes observados en la población de estudio fueron rojo y rojo obscuro presente en 35/100 y 25/100 respectivamente. El fenotipo negro se reportó en 16/100 aislados, el fenotipo muy negro se observó en 9/100 aislados, el fenotipo muy rojo en 11/100 y el fenotipo casi negro en 4/100 aislados. En la Figura 1 se puede ver los fenotipos obtenidos ordenadas de forma que se asemejen a la escala de Arciola et al. (2002), donde consta las seis categorías: muy rojo (Figura 1, A), rojo (Figura 1, B), rojo obscuro (Figura 1, C), casi negro (Figura 1, D), negro (Figura 1, E) y muy negro (Figura 1, F). 
Tabla 2. Cebadores utilizados en la detección de genes codificantes para la producción de biofilm en Staphylococcus aureus

\begin{tabular}{cccc}
\hline Cebadores* $^{*}$ & Secuencias del cebador & $\begin{array}{c}\text { Longitud del } \\
\text { producto }\end{array}$ & $\begin{array}{c}\text { Condiciones de } \\
\text { PCR }\end{array}$ \\
\hline icaA forward & $5^{\prime}$-ACACTTGCTGGCGCAGTCAA-3' & $188 \mathrm{pb}$ & $30 \mathrm{~s} 94^{\circ} \mathrm{C}$ \\
icaA reverse & $5^{\prime}$-TCTGGAACCAACATCCAACA-3' & & $30 \mathrm{~s} 55^{\circ} \mathrm{C}$ \\
& & & $45 \mathrm{~s} 72^{\circ} \mathrm{C}$ \\
\hline icaD forward & $5^{\prime}$-ATGGTCAAGCCCAGACAGAG-3' & $198 \mathrm{pb}$ & $30 \mathrm{ciclos}$ \\
icaD reverse & 5'-AGTATTTTCAATGTTTAAAGCAA- & & $30 \mathrm{~s} 72^{\circ} \mathrm{C}$ \\
& & & $30 \mathrm{~s} 55^{\circ} \mathrm{C}$ \\
& & & $45 \mathrm{~s} 72^{\circ} \mathrm{C}$ \\
& & & $30 \mathrm{ciclos}$ \\
\hline
\end{tabular}

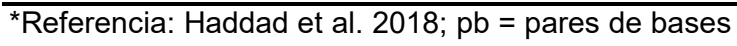

El número de aislados con fenotipos positivos por especie para la producción de biofilm (casi negro, negro, muy negro) fueron muy bajos. Para S. epidermidis, la prueba bioquímica reveló la producción de biofilm en 21/61 aislados que representa el 34,42\%, y para S. aureus, 8/39 aislados que representa el 20,51\%. Los 71 aislados restantes de S. aureus y S. epidermidis presentaron fenotipos negativos para la producción de biofilm con resultados de muy rojo, rojo y rojo obscuro.

Resultados por PCR.- El resultado de las reacciones de amplificación para S. epidermidis mostró un porcentaje mayor al 50,00 \% de la población con presencia de los genes icaA, icaB, icaD; mientras que para icaC fue menor al $50,00 \%$. En S. epidermidis el porcentaje de aislados positivos para icaA fue del 59,02\% (36/61) (Figura 2, A), 57,38 \% (35/61) para icaB (Figura 2, B), 42,62 \% (26/61) para icaC (Figura 2, C) y $52.46 \%$ (32/61) para icaD (Figura 2, D). En S. aureus el porcentaje de aislados positivos para los genes icaA (Figura 3, A) e icaD (Figura 3, B) fue del 87,18\% (34/39) para ambos genes.

El número de aislados con resultados positivos a la producción de biofilm y por especie es mayor con la determinación por PCR en relación con el análisis cualitativo. En S. epidermidis se registraron 36/61 (59,02\%) aislados y en S. aureus 35/39 (89,74\%) aislados positivos a la producción de biofilm.

En el primer hospital de Quito, 29/40 (72,50 \%) aislados fueron positivos a alguno de los 4 genes ica, distribuyéndose en 17 aislados de $S$. epidermidis y 12 aislados $S$. aureus. En el segundo hospital de Quito, 32/50 (64,00 \%) aislados fueron positivos a alguno de los cuatro genes, siendo 19 aislados S. epidermidis y 13 aislados S. aureus. En el hospital del Puyo, los 9 aislados de S. aureus fueron positivos a los genes ica. Incluyendo la cepa ATCC ${ }^{\circledR}$ fueron 71/100 aislados positivos dentro de la población.

Comparación de resultados de las pruebas cualitativas con los resultados de la PCR.- El número de aislados reconocidos mediante la prueba cualitativa positiva para la producción de biofilm con agar rojo Congo es menor a la cantidad de positivos obtenidos con las pruebas de PCR. Mediante la prueba cualitativa 29/100 (29,00 \%) aislados presentan los fenotipos: casi negro, negro o muy negro, que los califica como productores de biofilm, mientras que con las PCR se registraron 71/100 (71,00\%) aislados que tuvieron alguno de los 4 genes ica (Tabla 3). Sin embargo, 11 aislados que poseían un fenotipo positivo para la producción de biofilm en el agar rojo Congo, no obtuvieron resultados positivos a las amplificaciones de los genes codificantes a la producción de este polímero. 


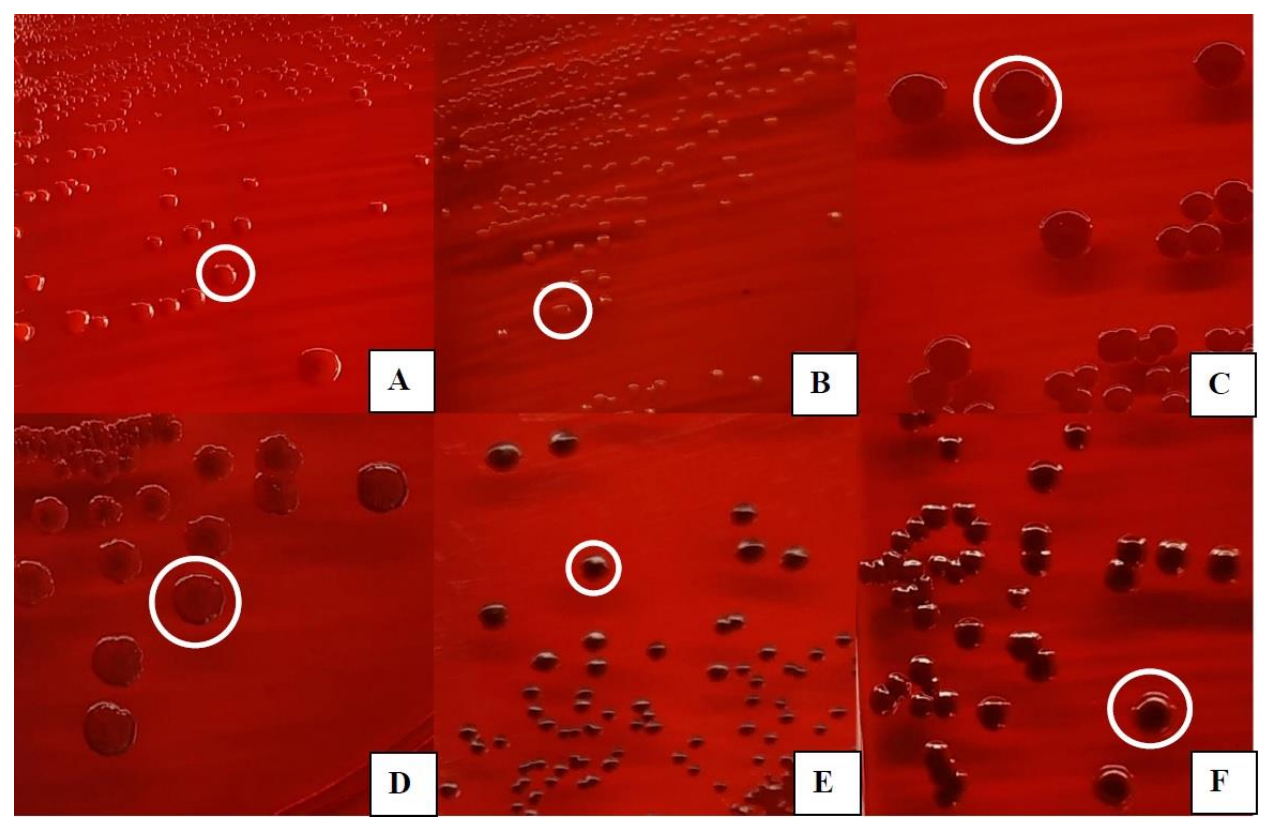

Figura 1. Patrón colorimétrico reconocido en las muestras colectadas. A) Muy rojo, CB-QCA 4588; B) Rojo, CB-QCA 4847; C) Rojo obscuro, CB-QCA 4714; D) Casi negro, CB-QCA 4620; E) Negro, CB-QCA 4814; F) Muy negro, CB-QCA 4659

\section{Discusión}

En la actualidad, se deben tomar en cuenta distintos factores al momento de tratar una infección bacteriana, ya que cada especie puede mostrar diferentes formas de combatir los agentes antimicrobianos. Los mecanismos primarios son las resistencias innatas, ya sean por: desactivación enzimática del agente, acumulación reducida del agente por afluencia reducida o eflujo incrementado, o distintos tipos de modificaciones del sitio blanco (Duijkeren et al. 2018).

De los distintos factores de virulencia que poseen las diversas especies bacterianas, tanto en S. epidermidis como en S. aureus, se puede observar un factor de virulencia en común, la producción de biofilm. Éste ha sido uno de los factores de virulencia que ha convertido a S. epidermidis como patógeno oportunista del ambiente hospitalario. La capacidad de producir biofilm, permite a S. epidermidis adherirse a varias superficies de aparatos médicos, resistir la acción de desinfectantes y antisépticos, y evitar el sistema inmune del hospedero, una vez que alcanzado al paciente (Otto 2009; Arciola et al. 2018). S. aureus, además de tener un arsenal de factores de virulencia, también posee los mismos genes ica para la producción de biofilm. Los genes icaA e icaD entre S. aureus y S. epidermidis poseen una similitud de 76 y $72 \%$ respectivamente (Rohde et al. 2001). Por esta razón no se pudo utilizar los mismos cebadores para ambas especies y solo se usaron los genes icaA e icaD para $S$. aureus.

En la presente investigación las pruebas de rojo Congo mostraron una variabilidad en los fenotipos presentes en la población. De estos, los dominantes fueron los fenotipos rojo y rojo obscuro, y en menor cantidad los fenotipos negros relacionados con la producción de biofilm. Considerando a los fenotipos casi negro, negro y muy negro como biofilm positivos, se identificó que el $34,43 \%$ de los aislados de $S$. epidermidis y el 20,51\% de los aislados de $S$. aureus fueron positivos a la presencia de biofilm. Esto contrasta con los resultados obtenidos por los análisis por $\mathrm{PCR}$, donde existieron un mayor número de aislados positivos a la presencia de genes codificantes para la producción de biofilm. Este resultado se puede deber a la necesidad de la bacteria a ser sometida a estrés ambiental o condiciones óptimas que estimulen a la bacteria a producir biofilm. Por ejemplo, la presencia de etanol, isopropanol, $\mathrm{NaCl}$ y un $\mathrm{pH}$ cercano a 7 favorecen la producción del polímero (O'Gara 2007; Luther et al. 2015; Tango et al. 2018). 


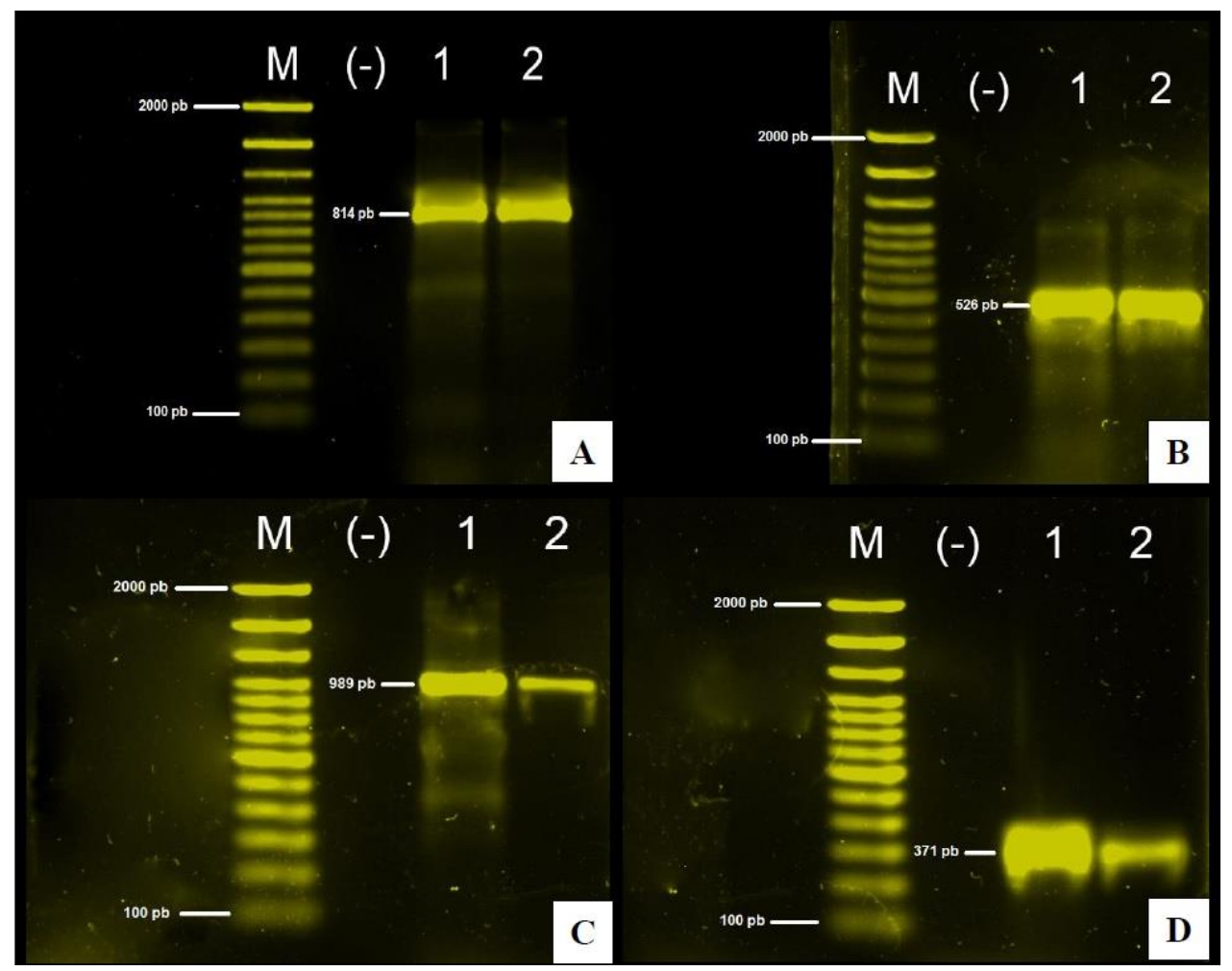

Figura 2. Geles representativos de los productos de amplificación obtenidos para los genes ica en S. epidermidis.

A) icaA (814 pb), M, marcador de peso molecular (100 pb); (-), control negativo; aislado 1, CB-QCA 4891; aislado 2, CB-QCA 4927;

B) icaB (526 pb), M, marcador de peso molecular (100 pb); (-), control negativo; aislado 1, CB-QCA 4891; aislado 2, CB-QCA 4927;

C) icaC (989 pb), M, marcador de peso molecular (100 pb); (-), control negativo; aislado 1, CB-QCA 4891; aislado 2, CB-QCA 4750;

D) icaD (371 pb), M, marcador de peso molecular (100 pb); (-), control negativo; aislado 1, CB-QCA 4891; aislado 2, CB-QCA 4827.

Las bacterias empleadas en esta investigación fueron sometidas a un tipo de estrés ambiental al ser cultivadas en agar manitol salado previamente a la inoculación en agar rojo Congo. Pero la expresión también depende de varios factores que están constantemente regulando la producción de biofilm. El gen icaR codifica al represor del gen icaA, que se adhiere a la región promotora del locus ica (Conlon et al.2002; O'Gara 2007). Otro regulador es el elemento móvil IS256 que inhibe la producción de biofilm cuando se acopla en distintas regiones del locus ica (Ziebuhr et al. 1999; Arciola et al. 2015; Arciola et al. 2018).

Por esta razón, es necesario complementar los estudios cualitativos con el análisis molecular de los genes asociados a la producción de biofilm. Con las reacciones de PCR se incrementó el número inicial de aislados positivos a la producción de biofilm de 29/100 aislados a 71/100 aislados. Aunque el método de agar rojo Congo es utilizado generalmente para confirmar la presencia de biofilm, no siempre se puede determinar exactamente si el aislado es positivo a la presencia de genes ica productores de biofilm (Lee et al. 2016). Por esto se han propuesto modificaciones al método del agar rojo Congo para volverlo más efectivo en la detección de biofilm incrementando el estrés a la bacteria. Existen una variedad de propuestas como cambiar el agar de Infusión Cerebro Corazón (BHI agar) por Caldo Tripticasa Soya (TSB) (Lee et al. 2016), o añadir $\mathrm{NaCl}$ (Kaiser et al. 2013).

El porcentaje de aislados positivos a la presencia de biofilm después de las pruebas por PCR se incrementó, tanto como para S. epidermidis como para S. aureus (Tabla 4). En la literatura se pueden observar patrones similares donde se reporta mayor porcentaje de aislados positivos para genes ica en S. aureus que en S. epidermidis. En estudios realizados por Calà et al. (2015), de una población de $S$. epidermidis proveniente de la piel de pacientes hospitalizados los resultados positivos fueron del 42,85\% (45/105 aislados). Estudios de Solati et al. (2015) obtuvieron 35/80 
aislados de S. epidermidis productores de biofilm provenientes de distintas muestras (orina 52,5 $\%$, sangre $28,75 \%$ y bolsas de diálisis $18,75 \%$ ). De éstos, existió una variación de presencia de genes relacionados con la cantidad de biofilm producido. Esto explicaría la variación y bajos positivos para en la presencia de los genes icaB e icaC en los aislados de S. epidermidis de la presente investigación.

Existe una variedad de resultados sobre la presencia de los genes ica en S. aureus. Mirzaee et al. (2014) estudiaron 63 aislados clínicos de S. aureus resistentes a meticilina (MRSA) y encontraron una prevalencia del 60,30 \% (38/63 aislados) para la presencia del gen icaA y del 100\% (63/63 aislados) para la presencia del gen icaD. En Knobloch et al. (2002) entre 82 aislados de cultivos de sangre y 26 nasales de $S$. aureus, la totalidad poseía los genes ica. En Rhode et al. (2001) esto se explica como una variación dependiente del origen de las muestras. Esto se podía notar en Arciola et al. (2001), donde solo el 61,00\% de su población de S. aureus provenientes de infecciones por catéteres poseían los genes icaA e icaD. Pero en el estudio de Arciola et al. (2005) con muestras obtenidas de prótesis ortopédicas, el porcentaje de positivos aumentó significativamente.

En esta investigación los aislados provienen de distintos tipos de muestras (sangre, punta de catéter, heridas, abscesos) y los porcentajes de resultados positivos varían, tanto por especie como por muestra; por lo que relacionar el porcentaje de positivos con el origen de la muestra no es posible.

Se observaron 11 aislados que poseían un fenotipo positivo para la producción de biofilm en agar rojo Congo y negativos para la presencia de genes ica. El color negro de las colonias en este agar se debe a la presencia de polisacáridos que componen el biofilm de tipo PIA, que dependen de la expresión de los genes ica. Por lo que los genes deben estar presentes, pero no se obtuvo amplificación por la PCR. Esto pudo haber ocurrido por dificultades en la digestión de la pared celular, ya que el protocolo de PROMEGA ${ }^{\oplus}$ recomienda usar una mezcla de $60 \mathrm{\mu L}$ de Lisozima $(10 \mathrm{mg} / \mathrm{mL})$ y $60 \mu \mathrm{L}$ de Lisostafina $(10 \mathrm{mg} / \mathrm{mL})$ para una buena lisis de la pared celular. En esta investigación se utilizó $120 \mu \mathrm{l}$ de Lisozima $(10 \mathrm{mg} / \mathrm{mL})$. Esto coincide con la baja concentración de ADN, medida en el NanoDrop ${ }^{\mathrm{TM}} 2000$ (Thermo Scientific ${ }^{\mathrm{TM}}$ ). Otra posibilidad pudo haber sido la fuerte presencia de biofilm en las colonias, esto pudo haber dificultado actividad enzimática de la Lisozima, de una manera similar en la que evade el contacto con los leucocitos en el cuerpo del hospedero (Arciola et al. 2018).

La presente investigación ha logrado comprobar que poblaciones de S. aureus y S. epidermidis provenientes de hospitales en Quito y el Puyo son capaces de producir biofilm de tipo PIA y los genes ica están presentes en un gran porcentaje de la población. En Kozitskaya et al. (2004) se

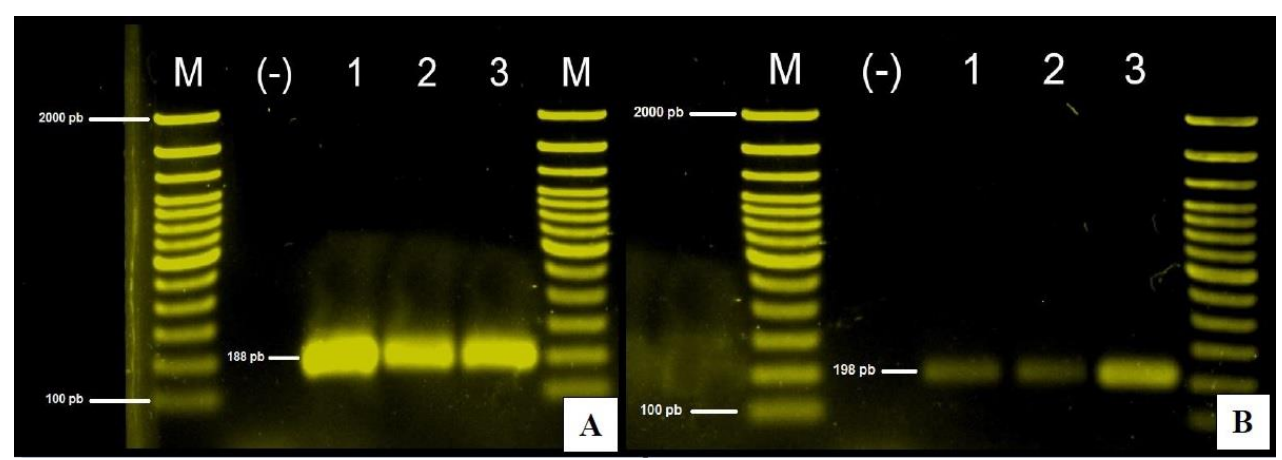

Figura 3. Geles representativos de los productos de amplificación obtenidos para los genes ica en S. aureus. A) icaA (188 pb), M, marcador de peso molecular (100 pb); (-), control negativo; aislado 1, CB-QCA 4584; aislado 2, CB-QCA 4751; aislado 3, CB-QCA 4583; B) ica D (198 pb), M, marcador de peso molecular (100 pb); (-), control negativo; aislado 1, CB-QCA 4584; aislado 2, CB-QCA 4751; aislado 3, CB-QCA 4583 
Tabla 3. Producción o no producción de biofilm definido por pruebas cualitativa y PCR

\begin{tabular}{|c|c|c|c|c|c|c|c|c|}
\hline \multirow[b]{2}{*}{ Código PUCE } & \multirow[b]{2}{*}{ Identificación } & \multirow[b]{2}{*}{ Hospital } & \multicolumn{4}{|c|}{ Genes asociados a la producción de Biofilm } & \multirow[b]{2}{*}{ Rojo Congo } & \multirow[b]{2}{*}{ Presencia } \\
\hline & & & $i c a A$ & $i c a B$ & $i c a C$ & $i c a D$ & & \\
\hline 4524 & S. aureus & H-Puyo & $1^{\S \S}$ & $\overline{s c}$ & sc & 1 & $\mathrm{cn}$ & $1^{\S}$ \\
\hline 4540 & S. epidermidis & H1-Quito & $0^{* *}$ & 0 & 0 & 0 & $\mathrm{n}$ & 1 \\
\hline 4556 & S. aureus & H-Puyo & 1 & sc & sc & 1 & r & $0^{*}$ \\
\hline 4566 & S. epidermidis & H1-Quito & 0 & 0 & 0 & 0 & ro & 0 \\
\hline 4569 & S. epidermidis & H1-Quito & 1 & 1 & 1 & 1 & $\mathrm{r}$ & 0 \\
\hline 4571 & S. aureus & H1-Quito & 1 & sc & sc & 1 & $\mathrm{n}$ & 1 \\
\hline 4574 & S. epidermidis & H2-Quito & 0 & 0 & 0 & 0 & $r$ & 0 \\
\hline 4576 & S. aureus & H2-Quito & 1 & sc & sc & 1 & $\mathrm{mr}$ & 0 \\
\hline 4577 & S. aureus & H1-Quito & 1 & sc & sc & 1 & $r$ & 0 \\
\hline 4583 & S. aureus & H2-Quito & 1 & sc & sc & 1 & $r$ & 0 \\
\hline 4584 & S. aureus & H2-Quito & 1 & sc & sc & 1 & ro & 0 \\
\hline 4587 & S. aureus & H2-Quito & 1 & sc & sc & 1 & ro & 0 \\
\hline 4588 & S. epidermidis & H2-Quito & 0 & 0 & 0 & 0 & $\mathrm{mr}$ & 0 \\
\hline 4592 & S. epidermidis & H2-Quito & 0 & 0 & 0 & 0 & $r$ & 0 \\
\hline 4598 & S. epidermidis & H2-Quito & 0 & 0 & 0 & 0 & $r$ & 0 \\
\hline 4613 & S. epidermidis & H1-Quito & 0 & 0 & 0 & 0 & $\mathrm{cn}$ & 1 \\
\hline 4615 & S. aureus & H1-Quito & 0 & sc & sc & 0 & $\mathrm{cn}$ & 1 \\
\hline 4616 & S. epidermidis & H1-Quito & 1 & 1 & 0 & 0 & $\mathrm{n}$ & 1 \\
\hline 4620 & S. epidermidis & H1-Quito & 1 & 1 & 0 & 1 & $\mathrm{mn}$ & 1 \\
\hline 4629 & S. epidermidis & H1-Quito & 1 & 1 & 1 & 1 & r & 0 \\
\hline 4634 & S. aureus & H2-Quito & 1 & sc & sc & 1 & $\mathrm{mr}$ & 0 \\
\hline 4636 & S. epidermidis & H2-Quito & 0 & 0 & 0 & 0 & $\mathrm{mn}$ & 1 \\
\hline 4653 & S. aureus & H2-Quito & 1 & sc & sc & 1 & $r$ & 0 \\
\hline 4655 & S. aureus & H2-Quito & 1 & sc & sc & 1 & ro & 0 \\
\hline 4656 & S. epidermidis & H2-Quito & 0 & 0 & 0 & 0 & $\mathrm{mn}$ & 1 \\
\hline 4659 & S. epidermidis & H2-Quito & 1 & 1 & 1 & 1 & $\mathrm{mn}$ & 1 \\
\hline 4681 & S. epidermidis & H2-Quito & 1 & 1 & 0 & 0 & $\mathrm{mr}$ & 0 \\
\hline 4682 & S. epidermidis & H2-Quito & 1 & 1 & 1 & 1 & $\mathrm{mr}$ & 0 \\
\hline 4695 & S. epidermidis & H2-Quito & 0 & 0 & 0 & 0 & $\mathrm{mn}$ & 1 \\
\hline 4696 & S. epidermidis & H2-Quito & 1 & 1 & 0 & 1 & r & 0 \\
\hline 4709 & S.epidermidis & H2-Quito & 1 & 1 & 0 & 1 & $r$ & 0 \\
\hline 4710 & S. epidermidis & H2-Quito & 1 & 1 & 1 & 1 & $\mathrm{n}$ & 1 \\
\hline 4713 & S. epidermidis & H1-Quito & 1 & 0 & 0 & 1 & $\mathrm{n}$ & 1 \\
\hline 4714 & S. aureus & H1-Quito & 1 & sc & sc & 1 & ro & 0 \\
\hline 4718 & S. epidermidis & H2-Quito & 1 & 1 & 1 & 1 & $\mathrm{mn}$ & 1 \\
\hline 4721 & S. epidermidis & H1-Quito & 0 & 0 & 0 & 0 & $r$ & 0 \\
\hline 4722 & S. aureus & H1-Quito & 1 & sc & sc & 1 & $\mathrm{mr}$ & 0 \\
\hline 4723 & S. aureus & H1-Quito & 1 & sc & sc & 1 & ro & 0 \\
\hline 4724 & S. aureus & H1-Quito & 1 & sc & sc & 1 & $r$ & 0 \\
\hline 4728 & S. epidermidis & H2-Quito & 1 & 1 & 1 & 1 & $r$ & 0 \\
\hline 4729 & S. epidermidis & H2-Quito & 0 & 0 & 0 & 0 & $\mathrm{mr}$ & 0 \\
\hline 4730 & S. epidermidis & H2-Quito & 0 & 0 & 0 & 0 & ro & 0 \\
\hline 4735 & S. epidermidis & H2-Quito & 0 & 0 & 0 & 0 & $r$ & 0 \\
\hline 4736 & S. epidermidis & H2-Quito & 1 & 1 & 1 & 1 & ro & 0 \\
\hline 4747 & S. epidermidis & H1-Quito & 1 & 1 & 1 & 1 & $r$ & 0 \\
\hline 4749 & S. aureus & H1-Quito & 1 & sc & sc & 1 & ro & 0 \\
\hline 4750 & S. epidermidis & H1-Quito & 1 & 1 & 1 & 1 & $\mathrm{n}$ & 1 \\
\hline 4784 & S. aureus & H2-Quito & 1 & sc & sc & 1 & ro & 0 \\
\hline 4798 & S. epidermidis & H2-Quito & 1 & 1 & 1 & 1 & $\mathrm{n}$ & 1 \\
\hline 4799 & S. epidermidis & H2-Quito & 1 & 1 & 1 & 1 & ro & 0 \\
\hline 4814 & S.epidermidis & H2-Quito & 0 & 0 & 0 & 0 & $\mathrm{n}$ & 1 \\
\hline 4827 & S. epidermidis & H2-Quito & 1 & 1 & 1 & 1 & $r$ & 0 \\
\hline
\end{tabular}


Continuación Tabla 3. Producción o no producción de biofilm definido por pruebas cualitativa y PCR

\begin{tabular}{|c|c|c|c|c|c|c|c|c|}
\hline \multirow[b]{2}{*}{ Código PUCE } & \multirow[b]{2}{*}{ Identificación } & \multirow[b]{2}{*}{ Hospital } & \multicolumn{4}{|c|}{ Genes asociados a la producción de Biofilm } & \multirow[b]{2}{*}{ Rojo Congo } & \multirow[b]{2}{*}{ Presencia } \\
\hline & & & $i c a A$ & $i c a B$ & $i c a C$ & $i c a D$ & & \\
\hline 4828 & S. aureus & H2-Quito & 1 & sc & SC & 1 & ro & 0 \\
\hline 4838 & S. epidermidis & H2-Quito & 0 & 0 & 0 & 0 & $\mathrm{n}$ & 1 \\
\hline 4839 & S. aureus & H2-Quito & 1 & sc & sc & 1 & $\mathrm{n}$ & 1 \\
\hline 4843 & S. epidermidis & H1-Quito & 1 & 1 & 1 & 0 & r & 0 \\
\hline 4845 & S. aureus & H1-Quito & 1 & sc & sc & 1 & ro & 0 \\
\hline 4847 & S. epidermidis & H1-Quito & 1 & 1 & 1 & 0 & $r$ & 0 \\
\hline 4857 & S. epidermidis & H2-Quito & 1 & 1 & 1 & 1 & $\mathrm{mn}$ & 1 \\
\hline 4858 & S. epidermidis & H2-Quito & 1 & 1 & 1 & 1 & $r$ & 0 \\
\hline 4869 & S. epidermidis & H2-Quito & 1 & 1 & 1 & 1 & ro & 0 \\
\hline 4873 & S. aureus & H1-Quito & 1 & sc & sc & 1 & $\mathrm{n}$ & 1 \\
\hline 4874 & S. aureus & H1-Quito & 1 & sc & sc & 1 & $\mathrm{mn}$ & 1 \\
\hline 4875 & S. epidermidis & H1-Quito & 1 & 1 & 1 & 1 & $r$ & 0 \\
\hline 4881 & S. aureus & H1-Quito & 1 & sc & sc & 1 & $r$ & 0 \\
\hline 4888 & S. aureus & H2-Quito & 1 & sc & sc & 1 & $\mathrm{mr}$ & 0 \\
\hline 4889 & S. aureus & H2-Quito & 1 & sc & sc & 1 & ro & 0 \\
\hline 4891 & S. epidermidis & H2-Quito & 1 & 1 & 1 & 1 & $\mathrm{n}$ & 1 \\
\hline 4892 & S. epidermidis & H2-Quito & 0 & 0 & 0 & 0 & $\mathrm{n}$ & 1 \\
\hline 4899 & S. epidermidis & H1-Quito & 1 & 1 & 1 & 1 & ro & 0 \\
\hline 4901 & S. epidermidis & H1-Quito & 0 & 0 & 0 & 0 & $\mathrm{mn}$ & 1 \\
\hline 4902 & S. epidermidis & H1-Quito & 0 & 0 & 0 & 0 & $r$ & 0 \\
\hline 4909 & S. epidermidis & H1-Quito & 1 & 1 & 0 & 1 & $\mathrm{n}$ & 1 \\
\hline 4911 & S. epidermidis & H1-Quito & 1 & 1 & 1 & 1 & $r$ & 0 \\
\hline 4926 & S. aureus & H1-Quito & 0 & sc & sc & 0 & $\mathrm{n}$ & 1 \\
\hline 4927 & S. epidermidis & H1-Quito & 1 & 1 & 1 & 1 & $\mathrm{mn}$ & 1 \\
\hline 4929 & S. epidermidis & H1-Quito & 1 & 1 & 0 & 1 & $r$ & 0 \\
\hline 4930 & S. epidermidis & H1-Quito & 1 & 1 & 1 & 1 & $r$ & 0 \\
\hline 4931 & S. aureus & H1-Quito & 0 & sc & sc & 0 & ro & 0 \\
\hline 4943 & S. epidermidis & H2-Quito & 1 & 1 & 0 & 1 & r & 0 \\
\hline 4944 & S. aureus & H1-Quito & 1 & sc & sc & 0 & ro & 0 \\
\hline 4947 & S. epidermidis & H1-Quito & 1 & 1 & 1 & 1 & $r$ & 0 \\
\hline 4949 & S. epidermidis & H2-Quito & 0 & 0 & 0 & 0 & r & 0 \\
\hline 4951 & S. epidermidis & H2-Quito & 0 & 0 & 0 & 0 & $r$ & 0 \\
\hline 4960 & S. aureus & H-Puyo & 1 & sc & sc & 1 & $r$ & 0 \\
\hline 4965 & S. aureus & H-Puyo & 1 & sc & sc & 1 & $r$ & 0 \\
\hline 4973 & S. aureus & H-Puyo & 1 & sc & sc & 1 & ro & 0 \\
\hline 4983 & S. epidermidis & H2-Quito & 1 & 1 & 0 & 1 & ro & 0 \\
\hline 4986 & S. epidermidis & H2-Quito & 0 & 0 & 0 & 0 & $r$ & 0 \\
\hline 4989 & S. aureus & H2-Quito & 1 & sc & sc & 1 & $\mathrm{mr}$ & 0 \\
\hline 4993 & S. aureus & H1-Quito & 0 & sc & sc & 0 & ro & 0 \\
\hline 4998 & S. epidermidis & H1-Quito & 0 & 0 & 0 & 0 & $r$ & 0 \\
\hline 5001 & S. epidermidis & H2-Quito & 1 & 1 & 1 & 1 & $\mathrm{mr}$ & 0 \\
\hline 5002 & S. epidermidis & H2-Quito & 0 & 0 & 0 & 0 & ro & 0 \\
\hline 5003 & S. epidermidis & H2-Quito & 0 & 0 & 0 & 0 & $r$ & 0 \\
\hline 5018 & S. aureus & H-Puyo & 1 & sc & sc & 1 & ro & 0 \\
\hline 5019 & S. aureus & H-Puyo & 1 & sc & sc & 1 & ro & 0 \\
\hline 5020 & S. aureus & H-Puyo & 1 & sc & sc & 1 & $\mathrm{mr}$ & 0 \\
\hline 5021 & S. aureus & H-Puyo & 1 & sc & sc & 1 & ro & 0 \\
\hline ATCC 25923 & S. aureus & - & 0 & sc & sc & 1 & $\mathrm{n}$ & 1 \\
\hline
\end{tabular}

${ }^{*}(0)$ ausencia de biofilm, ${ }^{\S}(1)$ presencia de biofilm; ${ }^{* *}(0)$ ausencia del gen; ${ }^{\S \S}(1)$ presencia del gen; (ATCC) Colección Americana de Cultivos Tipo, en inglés American Type Culture Collection; (CB-QCA) Colección Bacteriana Quito Católica; (cn) casi negro, (H1Quito) Hospital 1 de Quito, (H2-Quito) Hospital 2 de Quito, (H-Puyo) Hospital del Puyo, (mn) muy negro, (mr) muy rojo, (n) negro, (r) rojo, (ro) rojo obscuro; (sc) sin cebadores, Staphylococcus aureus no cuenta con cebadores para ica B y C. 
Tabla 4. Porcentaje de presencia de biofilm por prueba bioquímica y por PCR de $S$. aureus y $S$. epidermidis

\begin{tabular}{lcccccc}
\hline Especie/\# individuos & $\begin{array}{c}\text { Presencia por } \\
\text { bioquímica }\end{array}$ & $\begin{array}{c}\text { Presencia por } \\
\text { PCR }\end{array}$ & Gen icaA & Gen icaB & Gen icaC & Gen icaD \\
\hline S. aureus (39) & $20,51 \%$ & $89,74 \%$ & $87,18 \%$ & - & - & $87,18 \%$ \\
& $(8 / 39)$ & $(35 / 39)$ & $(34 / 39)$ & & & $(34 / 39)$ \\
S. epidermidis (61) & $34,42 \%$ & $59,02 \%$ & $59,02 \%$ & $57,38 \%$ & $42,62 \%$ & $52,46 \%$ \\
& $(21 / 61)$ & $(36 / 61)$ & $(36 / 61)$ & $(35 / 61)$ & $(26 / 61)$ & $(32 / 61)$ \\
\hline
\end{tabular}

relaciona la presencia de los genes icaADBC con resistencias a antibióticos y a la presencia de múltiples copias del elemento móvil IS256 en cepas clínicas, sugiriendo que este conjunto de elementos proporciona una variabilidad que le brinda una ventaja frente a cambios ambientales presentes en un hospital. La OMS ha catalogado a S. aureus como prioridad 2: elevada, debido a su creciente farmacorresistencia, por lo que es necesario buscar nuevos antibióticos (OMS 2017) o alternativas para su tratamiento (Zapotoczna et al. 2016).

El estudio de biofilm en estafilococos dentro de Latinoamérica se concentra en Brasil. Silva (2014) encontró una incidencia del 48,00 \% de cepas hospitalarias de S. epidermidis que presentaban los genes ica. En el estudio de Batistao et al. (2016) el 44,00 \% de su población de S. aureus presentaban genes ica.

Dentro de Ecuador no existen estudios de biofilm en S. aureus y S. epidermidis. Pero existen estudios sobre los grupos clonales de S. aureus circulantes en el país con los cuales podemos relacionar la presencia de biofilm. Según Zurita et al. (2016) los clones de S. aureus USA300-LV y USA600 fueron encontrados en el país. Estos poseen una diversidad de cepas capaces de producir biofilm fuertes o débiles (King et al. 2016).

Conociendo los grupos clonales de S. aureus y su capacidad de producir biofilm presentes en el país, se podría esperar que existan varias resistencias a antibióticos transferidas entre $S$. aureus y S. epidermidis. Esto debido a que ambas bacterias suelen compartir nichos y el biofilm es un ambiente propicio que mejora la capacidad de transferencia horizontal de material genético (Savage et al. 2013; Haaber et al. 2017). La transferencia de resistencias a aminoglucósidos y a Linezolid entre S. aureus y S. epidermidis ha sido documentada en varios estudios (Haaber et al. 2017; Cafini et al. 2016), por lo que el crecimiento de S. epidermidis como un patógeno casual en hospitales es de esperarse.

Comprender el funcionamiento del locus ica nos puede brindar opiniones sobre tratamientos terapéuticos a seguir en caso de infecciones con bacterias productoras de biofilm, para lo que se suele recomendar remoción quirúrgica del implante infectado y administración de vancomicina en caso de ser resistente a la meticilina (MRSA) (Archer et al. 2011). McCarthy et al. (2015) al relacionar la producción de biofilm en aislados clínicos de $S$. aureus resistentes a la meticilina (MRSA) y sensibles a la meticilina (MSSA), notaron que los aislados sensibles producían biofilm ica-dependiente, mientras que los resistentes formaban biofilm ica-independientes, indicando que cuando las bacterias adquieren la resistencia prefieren producir biofilm del tipo proteico (ica-independiente) al biofilm tipo polisacárido (ica-dependiente).

El estudio del biofilm de tipo PIA es un área que aún requiere de mucha investigación. Todavía se desconoce si los genes pueden ser transferidos horizontalmente (Kozitskaya et al. 2005) o de tratamientos efectivos. Para futuros proyectos se podría evaluar la relación de la producción de biofilm con resistencias a otro tipo de antibióticos como en Kozitskaya et al. (2004) dentro del país, ya que conocemos que existen cepas capaces de producir biofilm con resistencias a algunos antibióticos (Batistao et al. 2016). Existen estrategias terapéuticas que se encuentran en fase pre-clínica como péptidos antimicrobianos, bacteriófagos, enzimas degradantes de biofilm o bloqueadores de quorum sensing, pero aún no se logra alcanzar el objetivo al $100 \%$ 
(Otto 2019) por lo que la investigación debe continuar para prevenir las complicaciones en el tratamiento de infecciones hospitalarias asociadas a S. aureus o S. epidermidis.

\section{Conclusiones}

-Los aislados clínicos de S. aureus y S. epidermidis provenientes de procesos infecciosos de hospitales de tercer nivel de ciudades de Quito y el Puyo y tiene capacidad de producir biofilm.

-Se identificó que una tercera parte $(29,00 \%)$ de aislados de S. aureus y S. epidermidis son productores de biofilm mediante la prueba cualitativa en agar rojo Congo.

-Se identificó que la gran mayoría $(71,00 \%)$ de los aislados clínicos de S. aureus y S. epidermidis presentan los genes productores de biofilm expresando, incluyendo la cepa de referencia S. aureus ATCC ${ }^{\otimes} 25923$.

-La identificación de la formación de biofilm mediante la prueba de rojo Congo no es precisa al identificar aislados clínicos de S. aureus y S. epidermidis capaces de producir biofilm icadependiente, pues la expresión de biofilm es muy variada, como se pudo evidenciar en los distintos fenotipos mostrados en rojo Congo.

\section{Agradecimientos}

Un cordial agradecimiento a la Pontificia Universidad Católica del Ecuador por el financiamiento a través de proyecto PUCE 2018 Código 013020 y desde el 2019 QINV0017-IINV529010100. También al Laboratorio de Microbiología de la escuela de Biología por la apertura y disponibilidad para el desarrollo de este trabajo de investigación. A todos los integrantes del laboratorio de Microbiología por el apoyo y la confianza depositada en el desarrollo del presente trabajo. Agradecemos profundamente a los directivos de las tres casas de salud quienes gentilmente donaron los aislados que se incluyeron en este estudio.

\section{Declaración de conflicto de intereses y contribución de los autores}

Los autores declaramos que no tenemos conflicto de intereses y nuestras contribuciones fueron las siguientes:

Andrés Sanguano: diseño experimental del estudio, adquisición y colección de datos. análisis e interpretación de datos, redacción de la versión inicial y final del manuscrito.

Iliana Alcocer: concepción y diseño del estudio, adquisición y colección de datos, redacción de la versión inicial del manuscrito, revisión del manuscrito y gestión de financiamiento.

María Fernanda Yauri: adquisición y colección de datos, concepción y diseño del estudio, análisis e interpretación de datos y revisión de la versión inicial del manuscrito.

\section{Referencias bibliográficas}

Archer N, Mazaitis M, Costerton J, Leid J, Powers M, Shirtliff M. 2011. Staphylococcus aureus biofilms: properties, regulation, and roles in human disease. Virulence. 2(5): 445-459.

Arciola C, Baldassarri L, Montanaro L. 2001. Presence of icaA and icaD Genes and slime production in a collection of Staphylococcal strains from catheter-associated infections. Journal of Clinical Microbiology. 39(6): 2151-2156.

Arciola C, Campoccia D, Montanaro L. 2018. Implant infections: adhesion, biofilm formation and immune evasion. Nature Reviews Microbiology. 16(7): 397.

Arciola C, Campoccia D, Gamberini S, Cervellati M, Donati E, Montanaro L. 2002. Detection of slime production by means of an optimised Congo red agar plate test based on a colourimetric scale in Staphylococcus epidermidis clinical isolates genotyped for ica locus. Biomaterials. 23(21): 4233-4239.

Arciola C, Campoccia D, Ravaioli S, Montanaro L. 2015. Polysaccharide intercellular adhesin in biofilm: structural and regulatory aspects. Frontiers in cellular and infection microbiology. 5(7): 1-10. 
Arciola C, Gamberini S, Campoccia D, Visai L, Speziale P, Baldassarri L, Montanaro L. 2005. A multiplex PCR method for the detection of all five individual genes of ica locus in Staphylococcus epidermidis. A survey on 400 clinical isolates from prosthesis区associated infections. Journal of Biomedical Materials Research Part A: An Official Journal of The Society for Biomaterials, The Japanese Society for Biomaterials, and The Australian Society for Biomaterials and the Korean Society for Biomaterials. 75(2): 408-413.

Batistao D, Amaral de Campos P, Camilo N, Royer S, Araújo B, Naves K, Martins M, Pereira M, Henriques M, Gontijo-Filho P, Botelho C, Oliveira R, Ribas R. 2016. Biofilm formation of Brazilian meticillin-resistant Staphylococcus aureus strains: prevalence of biofilm determinants and clonal profiles. Journal of Medical Microbiology. 65(4): 286-297.

Cafini F, Nguyen L, Higashide M, Román F, Prieto J, Morikawa K. 2016. Horizontal gene transmission of the cfr gene to MRSA and Enterococcus: role of Staphylococcus epidermidis as a reservoir and alternative pathway for the spread of linezolid resistance. Journal of Antimicrobial Chemotherapy. 71(3): 587-592.

Calà C, Amodio E, Di Carlo E, Virruso R, Fasciana T, Giammanco A. 2015. Biofilm production in Staphylococcus epidermidis strains, isolated from the skin of hospitalized patients: genetic and phenotypic characteristics. New Microbiol. 38(4): 521-9.

Carr A, Daley M, Givens Merkel K, Rose D. 2018. Clinical Utility of Methicillin囚Resistant Staphylococcus aureus Nasal Screening for Antimicrobial Stewardship: A Review of Current Literature. Pharmacotherapy: The Journal of Human Pharmacology and Drug Therapy. 38(12): 1216-1228.

Cavallini R. 2005. Bacteriología general: Principios y prácticas de laboratorio. [Internet]. San José (CR). Editorial Universidad de Costa Rica. Disponible en: https://books.google.com.ec/books?id= vwBOfgirgNOC\&printsec $=$ frontcover\&dq $=$ Rodr\%C3\%ADguez+E, + Gamboa $+M,+$ Hern\%C3\%A1n dez+F,+Garc\%C3\%ADa+J.+2006.+Bacteriolog\%C3\%ADa+general:+Principios+y+pr\%C3\%A1cti cas+de+laboratorio.+Costa+Rica:+Editorial+Universidad+de+Costa+Rica.\&hl=es\&sa=X\&ved=2 ahUKEwjvxrLmz6HtAhV4SzABHesvAb0Q6AEwAXoECAIQAg\#v=onepage\&q\&f=false

Conlon K, Humphreys H, O'Gara J. 2002. icaR encodes a transcriptional repressor involved in environmental regulation of ica operon expression and biofilm formation in Staphylococcus epidermidis. Journal of bacteriology. 184(16): 4400-4408.

Dong Y, Speer C, Glaser K. 2018. Beyond sepsis: Staphylococcus epidermidis is an underestimated but significant contributor to neonatal morbidity. Virulence. 9(1):621-633.

Van Duijkeren E, Schink A, Roberts M, Wang Y, Schwarz S. 2018. Mechanisms of bacterial resistance to antimicrobial agents. Antimicrobial Resistance in Bacteria from Livestock and Companion Animals: 51-82.

Freeman D, Falkiner F, Keane C. 1989. New method for detecting slime production by coagulase negative staphylococci. Journal of Clinical Pathology. 42(8): 872-874.

Granslo H. 2012. Staphylococcus epidermidis-virulence factors and innate immune response [thesis]. [Tromsø, (NO)]. Universidad de Tromsø.

Haaber J, Penadés J, Ingmer H. 2017. Transfer of antibiotic resistance in Staphylococcus aureus. Trends in microbiology. 25(11): 893-905.

Haddad O, Merghni A, Elargoubi A, Rhim H, Kadri Y, Mastouri M. 2018. Comparative study of virulence factors among methicillin resistant Staphylococcus aureus clinical isolates. BioMed Central Infectious Diseases. 18(1): 560. 
Heilmann C, Ziebuhr W, Becker K. 2019. Are coagulase-negative staphylococci virulent?. Clinical Microbiology and Infection. 25(9): 1071-1080.

Hennig S, Ziebuhr W. 2008. A transposase-independent mechanism gives rise to precise excision of IS256 from insertion sites in Staphylococcus epidermidis. Journal of bacteriology. 190(4): 1488-1490.

Jaśkiewicz M, Janczura A, Nowicka J, Kamysz W. 2019. Methods Used for the Eradication of Staphylococcal Biofilms. Antibiotics. 8(4): 174.

Ji Y, editor. 2007. Methicillin-resistant Staphylococcus aureus (MRSA) protocols. Volumen 1. New Jersey: Humana Press.

Kaiser T, Pereira E, dos Santos K, Maciel E, Schuenck R, Nunes A. 2013. Modification of the Congo red agar method to detect biofilm production by Staphylococcus epidermidis. Diagnostic microbiology and infectious disease. 75(3): 235-239.

King J, Kulhankova K, Stach C, Vu B, Salgado-Pabón W. 2016. Phenotypes and virulence among Staphylococcus aureus USA100, USA200, USA300, USA400, and USA600 clonal lineages. mSphere. 1(3).

Kleinschmidt S, Huygens F, Faoagali J, Rathnayake I, Hafner L. 2015. Staphylococcus epidermidis as a cause of bacteremia. Future Microbiology. 10(11): 1859-1879.

Knobloch J, Horstkotte M, Rohde H, Mack D. 2002. Evaluation of different detection methods of biofilm formation in Staphylococcus aureus. Medical microbiology and immunology. 191(2): 101-106.

Knobloch K, Von Osten H, Horstkotte M, Rohde H, Mack D. 2008. Biofilm formation is not necessary for development of quinolone-resistant"persister" cells in an attached Staphylococcus epidermidis population. The International Journal of Artificial Organs. 31(9): 752-760.

Koneman E, Allen S. 2008. Koneman. Diagnostico Microbiologico: Texto y Atlas en Color. Sexta edición. Buenos Aires(ARG): Editorial Médica Panamericana S.A.

Kozitskaya S, Cho S, Dietrich K, Marre R, Naber K, Ziebuhr W. 2004. The bacterial insertion sequence element IS256 occurs preferentially in nosocomial Staphylococcus epidermidis isolates: association with biofilm formation and resistance to aminoglycosides. Infection and immunity. 72(2): 1210-1215.

Kozitskaya S, Olson M, Fey P, WitteW, Ohlsen K, ZiebuhrW. 2005. Clonal analysis of Staphylococcus epidermidis isolates carrying or lacking biofilm-mediating genes by multilocus sequence typing. Journal of clinical microbiology. 43(9): 4751-4757.

Lee J, Bae Y, Han A, Lee S. 2016. Development of Congo red broth method for the detection of biofilm-forming or slime-producing Staphylococcus sp. Lebensmittel-Wissenschaft \& Technologie. 73: 707-714.

Lim S, Lee D, Kwak W, Shin H, Ku H, Lee J, Lee G, Kim H, Choi S, Ryu S, Lee J. 2015. Comparative genomic analysis of Staphylococcus aureus FORC_001 and S. aureus MRSA252 reveals the characteristics of antibiotic resistance and virulence factors for human infection. Journal of Microbiology and Biotechnology. 25(1): 98-108.

Luther M, Bilida S, Mermel L, LaPlante K. 2015. Ethanol and isopropyl alcohol exposure increases biofilm formation in Staphylococcus aureus and Staphylococcus epidermidis. Infectious diseases and therapy. 4(2): 219-226.

McCarthy H, Rudkin J, Black N, Gallagher L, O'Neill E, O'Gara J. 2015. Methicillin resistance and 
the biofilm phenotype in Staphylococcus aureus. Frontiers in cellular and infection microbiology. 5(1): 1-9.

Mirzaee M, Najar Peerayeh S, Ghasemian A. 2014. Detection of icaABCD genes and biofilm formation in clinical isolates of methicillin resistant Staphylococcus aureus. Iranian Journal of Pathology. 9(4): 257-262.

O'Gara J. 2007. ica and beyond: biofilm mechanisms and regulation in Staphylococcus epidermidis and Staphylococcus aureus. Federation of European Microbiological Societies Microbiology Letters. 270(2): 179-188.

Oliveira W, Silva P, Silva R, Silva G, Machado G, Coelho L, Correia M. 2018. Staphylococcus aureus and Staphylococcus epidermidis infections on implants. Journal of Hospital Infection. 98(2): 111117.

Organización Mundial de la Salud (OMS). 2017. La OMS publica la lista de las bacterias para las que se necesitan urgentemente nuevos antibióticos [Internet]. Comunicado de Prensa de la OMS; [citado 2020 Feb 5]. Disponible en: http://www.who.int/mediacentre/news/releases/2017/ bacteria-antibiotics-needed/es/

Otto M. 2009. Staphylococcus epidermidis-the'accidental'pathogen. Nature Reviews Microbiology. 7(8): 555.

Otto M. 2019. Staphylococcal biofilms. Gram®Positive Pathogens: 699-711.

Pahissa A. 2009. Infecciones producidas por Staphylococcus aureus. [Internet]. Barcelona (ESP). Marge Books. Disponible en: https://books.google.com.ec/books?id=qFRukXHQX $6 Q C \& p g=P A 6 \& d q=$ Pahissa + A.$+2009 .+$ Infecciones + producidas + por + Staphylococcus $+a$ ureus.+Barcelona, + Espa\%C3\%B1a,+Marge+Books.\&hl=es\&sa=X\&ved=2ahUKEwjftcPyzq HtAhVRVTABHbjOB-gQ6AEwAHoECAUQAg\#v=onepage\&q=Pahissa\%20A.\%202009.\%20 Infecciones\%20producidas\%20por\%20Staphylococcus\%20aureus.\%20Barcelona\%2C\%20 Espa\%C3\%B1a\%2C\%20Marge\%20Books.\&f=false

Paluch-Oleś J, Magryś A, Kozioł-Montewka M, Niedzielski A, Niedźwiadek J, Niedzielska G, Kotowski M. 2011. The phenotypic and genetic biofilm formation characteristics of coagulasenegative staphylococci isolates in children with otitis media. International Journal of Pediatric Otorhinolaryngology. 75(1): 126-130.

Petrelli D, Zampaloni C, d'Ercole S, Prenna M, Ballarini P, Ripa S, Vitali L. 2006. Analysis of different genetic traits and their association with biofilm formation in Staphylococcus epidermidis isolates from central venous catheter infections. European Journal of Clinical Microbiology and Infectious Diseases. 25(12): 773-781.

Rohde H, Knobloch J, Horstkotte M, Mack D. 2001. Correlation of Staphylococcus aureus icaADBCgenotype and biofilm expression phenotype. Journal of Clinical Microbiology. 39(12): 4595-4596.

Ruano C, Maldonado J, Salazar R. 2004. Frecuencia de infección nosocomial en terapia intensiva: datos del proyecto PIN-FCM. Revista Cubana de Higiene y Epidemiología. 42(1)

Santos A, Galdino A, Mello T, Ramos L, Branquinha M, Bolognese A, Neto J y Roudbary M. 2018. What are the advantages of living in a community? A microbial biofilm perspective! Memórias do Instituto Oswaldo Cruz. 113(9).

Savage V, Chopra I, O'Neill A. 2013. Staphylococcus aureus biofilms promote horizontal transfer of antibiotic resistance. Antimicrobial agents and chemotherapy. 57(4): 1968-1970.

Silva Filho R. 2014. Produção de biofilme em amostras clínicas de S. epidermidis: influência de 
concentrações subinibitórias de antissépticos (etanol e clorexidina) e associação com potenciais marcadores de virulência (Disertación Doctoral). [Rio de Janeiro (BR)]: Fundação Oswaldo Cruz. Instituto Nacional de Controle de Qualidade em Saúde. Recuperado de: https://www.arca. fiocruz.br/handle/icict/10997

Solati S, Tajbakhsh E, Khamesipour F, Gugnani H. 2015. Prevalence of virulence genes of biofilm producing strains of Staphylococcus epidermidis isolated from clinical samples in Iran. Applied Microbiology Express. 5(1): 47.

Tango C, Akkermans S, Hussain M, Khan I, Van Impe J, Jin Y, Oh D. 2018. Modeling the effect of pH, water activity, and ethanol concentration on biofilm formation of Staphylococcus aureus. Food microbiology. 76: 287-295.

Traisaeng S, Herr D, Kao H, Chuang T, Huang C. 2019. A derivative of butyric acid, the fermentation metabolite of Staphylococcus epidermidis, inhibits the growth of a Staphylococcus aureus strain isolated from atopic dermatitis patients. Toxins. 11(6): 311.

Zapotoczna M, O’Neill E, O'Gara J. 2016. Untangling the diverse and redundant mechanisms of Staphylococcus aureus biofilm formation. PLoS pathogens. 12(7): e1005671.

Ziebuhr W, Krimmer V, Rachid S, Lößner I, Götz F, Hacker J. 1999. A novel mechanism of phase variation of virulence in Staphylococcus epidermidis: evidence for control of the polysaccharide intercellular adhesin synthesis by alternating insertion and excision of the insertion sequence element IS256. Molecular Microbiology. 32(2): 345-356.

Zurita J, Barba P, Ortega-Paredes D, Mora M, Rivadeneira S. 2016. Local circulating clones of Staphylococcus aureus in Ecuador. Brazilian Journal of Infectious Diseases. 20(6): 525-533. 